\title{
EVALUATION OF RESULT OF TITANIUM ELASTIC NAILING IN PAEDIATRICS DIAPHYSEAL FRACTURE
}

\author{
Abhijit Sarkar1, Rakesh Rajput², Tapan Kr. Chattopadhay³
}

${ }^{1}$ Associate Professor, Department of Orthopaedics, Tripura Medical College.

${ }^{2}$ Associate Professor, Department of Orthopaedics, Tripura Medical College.

${ }^{3}$ Professor, Department of Orthopaedics, Tripura Medical College.

ABSTRACT
BACKGROUND
The management of paediatric femoral shaft fractures has evolved towards a more operative approach in the present decade. It
has been noticed that problems such as angulations, malrotation and limb length discrepancy cannot be effectively tackled by non-
operative treatment all the time.

\section{AIMS AND OBJECTIVES}

This is a prospective study to show titanium classic nailing in femoral fractures in children, is a single procedure and at the same time effective in perspective of early weight bearing, short hospital stay and better control of angulations, malrotation and leg length discrepancy.

\section{MATERIALS AND METHODS}

22 children (18 boys and 4 girls) aged 6-16 years with recent femoral diaphyseal fracture were stabilized with titanium elastic nail. All the nails were introduced through retrograde approach under image intensifier. Patients were evaluated using Flynn's scoring criteria. ${ }^{1}$ Statistical analysis was done using Fisher's exact test.

\section{RESULTS}

All 22 patients were evaluated after a mean 26 months (14-36 months) of followup. Radiological unions were achieved in a mean time of 8.2 weeks. Full weight bearing was possible in a mean time of 8.7 weeks. Mean duration of stay in hospital was 9.7 days. The results were excellent in 15 patients, good in 6 patients and poor in 1 patient.

\section{CONCLUSION}

Intramedullary fixation of diaphyseal fracture in children of 6-16 years with titanium elastic nail is a simple and effective method with low complication rate.

\section{KEYWORDS}

Titanium Elastic Nailing, Intramedullary, Paediatric Femoral Fracture.

HOW TO CITE THIS ARTICLE: Sarkar A, Rajput R, Chattopadhay TK. Evaluation of result of titanium elastic nailing in paediatrics diaphyseal fracture. J. Evolution Med. Dent. Sci. 2016;5(24):1310-1312, DOI: 10.14260/jemds/2016/306

\section{INTRODUCTION}

Femoral shaft fracture comprises of $2 \%$ of all fractures in children. There is little disagreement regarding the treatment of younger children below 6 years of age and these can be treated conservatively.2,3,4 Older children show good result with locked intramedullary femoral nailing. For children of middle age group between 6-16 years, there is a wide variety of surgical and non-surgical treatment options available. 5

Over the past three decades the advantages of fixation and rapid mobilization has increasingly been recognized.6,7,8 Intramedullary rigid nailing indicated for adults are associated with complication like premature closer of the greater trochanteric physis leading to coxa valga, avascular necrosis of the capital femoral epiphysis, leg length discrepancy, etc. Open reduction and internal fixation with plates and screws have known complications like infections, fracture below the plate,

Financial or Other, Competing Interest: None.

Submission 19-02-2016, Peer Review 02-03-2016,

Acceptance 05-03-2016, Published 24-03-2016.

Corresponding Author:

Dr. Abhijit Sarkar,

Associate Professor,

Department of Orthopaedics,

Tripura Medical College,

Agartala-14.

E-mail: amarkanti@yahoo.com

DOI: $10.14260 /$ jemds/2016/306
Stress fracture and refracture, hardware failure, etc.9,10 TENS is an ideal fixation device for paediatric femur fracture due to ease of use and it functions as an internal splint providing three point fixation.11,12 It does not disturb the fracture haematoma and thus provide biological fixation. The elasticity and stress distribution of the flexible nails facilitates the callus formation. Titanium also has excellent bio-compatibility. The perceived advantage of this technique includes early union due to repeated micromotion at fracture site, respect for the physis, early mobilization, early weight bearing, scar acceptance, easy implant removal and high patient satisfaction rate. $2,6,13,11$ We report a prospective study with the objective of evaluating the role and efficacy of titanium elastic nail in selected cases of femoral diaphyseal fractures in the 6-16 years' age group.

\section{MATERIALS AND METHODS}

22 children ( 18 boys and 4 girls) in the age range of $6-16$ years (Average 10.8 years) with recent ( $<3$ days) femoral shaft fracture were stabilized with titanium elastic nail (TENS) between January 2010 to February 2013. Most of the fractures were due to road traffic accident. Associated injuries were seen in 5 cases. Open fractures were excluded. None of the patient had neurovascular lesion. Associated injuries were seen in 6 cases. According to AO classification 17 were in $32 \mathrm{~A}$ (77.3\%), 4 were in $32 \mathrm{~B}(18.2 \%)$ and 1 patient was in $32 \mathrm{C}$ 
(4.5\%). Majority of the patients (18) underwent surgery within 7 days. The surgery was performed under general anaesthesia with the patients on the fracture table in supine position and image intensifier was used throughout the procedure; 2 titanium elastic nails of identical diameter were used ( 16 of Adler and 8 of Synthes).

The diameter of the individual nail was selected as per Flynn et al's formula (Diameter of nail=width of the narrowest point of the medullar canal on anteroposterior and lateral view $\mathrm{x} 0.4 \mathrm{~mm}$ ) and intraoperative assessment. The diameter of the nail was chosen, so that each nail occupies at least $1 / 3^{\text {rd }}$ to $40 \%$ of the medullary cavity. Fractures were reduced using image intensifier guidance. Nails were inserted in retrograde fashion with medial and lateral incision $2.5-3.5 \mathrm{~cm}$ above the physis. The nails were prebent sufficiently, so that apex of the bowed nails rested at the same level on the fracture site to ensure a good equal recoil force. The tip of the nail that entered from the lateral femoral cortex came to rest just distal to trochanteric epiphysis.

The opposite nail was made to lie in the same level, but pointing towards the calcar region of femoral neck. Distally, the nails were cut so that $1 \mathrm{~cm}$ of the nail remains outside the cortex. Postoperatively, patient was nursed in supine position with the leg elevated on a pillow. Long knee brace were used in 2 cases of distal third fracture, where fixation was not adequate. Patients were mobilized without weight bearing on the $5^{\text {th }}$ to $7^{\text {th }}$ Postoperative Day (POD). Partial as weight bearing was started at 3 weeks and full weight bearing by $6-8$ weeks depending on the fracture configuration, callus response and associated injuries.

All the patients were followed radiologically as well as clinically until fracture healed and for any complications statistical analysis was done using Fisher's exact test to evaluate

1. The significance of association between the occurrence of skin site irritations and by long, untrimmed nail ends.

2. Association of angulation of fracture with smaller and mismatched nail diameter.

3. Outcome between patients $<10$ years and $>10$ years. The results were evaluated using Flynn et al. scoring criteria for TEN (Table 1), nails were removed 6-8 months postsurgery, when fracture line were no longer visible radiologically.

The Scoring Criteria with Titanium Elastic Nails. ${ }^{1}$

\begin{tabular}{|c|c|c|c|}
\hline $\begin{array}{c}\text { Limb } \\
\text { Length } \\
\text { Discrepancy }\end{array}$ & $\begin{array}{c}\text { Excellent } \\
\mathbf{<} \mathbf{~} \mathbf{~ c m}\end{array}$ & $\begin{array}{c}\text { Successful } \\
\mathbf{< 2 . 0} \mathbf{~ c m}\end{array}$ & Poor $\mathbf{~ 2 . 0 ~} \mathbf{~ c m}$ \\
\hline $\begin{array}{c}\text { Sequence } \\
\text { disorder }\end{array}$ & 5 degrees & 10 degrees & $>10$ degrees \\
\hline Pain & Absent & Absent & Present \\
\hline Complication & Absent & Mild & $\begin{array}{c}\text { Major } \\
\text { andication } \\
\text { andor extended } \\
\text { period for } \\
\text { resolvable } \\
\text { morbidity }\end{array}$ \\
\hline
\end{tabular}

\section{RESULTS}

The median duration of surgery was $35 \mathrm{~min}$. The mean hospital stay was 9.7 days. Average union time of fracture was 8.2 weeks. All 22 patients were available for evaluation after a mean 26 months (11-36 months) of following. Radiological unions were achieved in all cases in a mean time 8.2 weeks (612 weeks). The results were excellent in 15 patients, $68 \%$ good in 6 patients $27 \%$ and poor in 1 patient $5 \%$ as per the Flynn et al. scoring criteria. Two patients had valgus angulations, 12 degrees and 6 degrees each; one patient had valgus angulations 15 degrees; entry site irritation occurred in 4 patients. Two patients had skin breakdown at entry site, which led to superficial infection. The infection resolved with 7 days oral course of cephalosporin. Limb lengthening of less than 1.5 were found in 3 cases, which were insignificant clinically. Result was better for children, less than 10 years of age. Functional range of movement of knee was achieved in an average of 8.2 weeks (6-30 weeks).

\section{Pre-Operative X-ray of Right Femur of 6 years Old Boy}

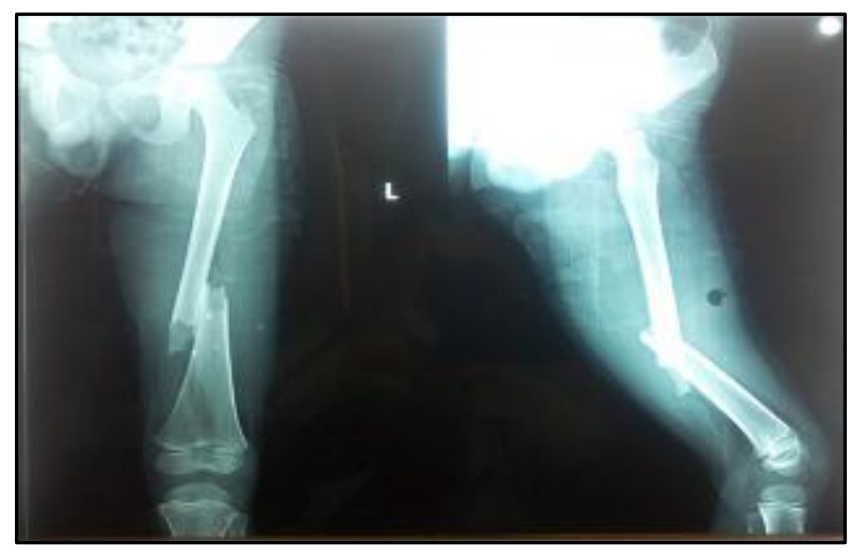

Post-Operative X-ray of Right Femur of 6 years Old Boy

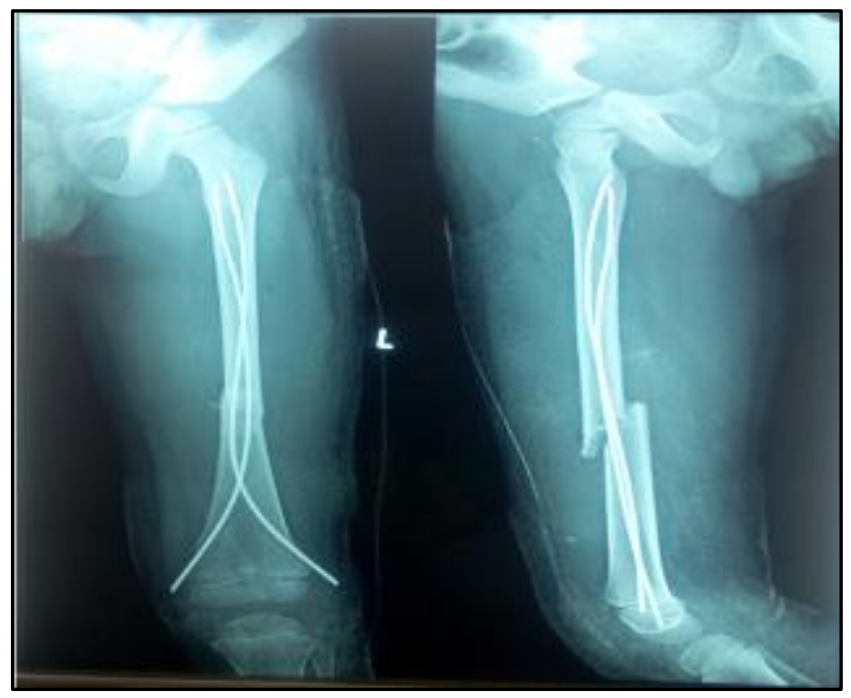

\section{DISCUSSION}

The femoral shaft fracture in children remained a constant challenge to the orthopaedics fraternity. Conservative treatment which was the earlier treatment was found to have many complications such as mal-union, joint stiffness, delay in functional recovery and also prolonged hospitalization causing financial loss to the family. 
During the past few decades some form of internal fixation as plate fixation rigid intramedullary nailing, Enders nailing and titanium nailing has been advocated, controversy regarding the ideal implant to treat paediatric femoral fractures still exists. The ideal device for the treatment of most femoral fracture in children would be a simple load sharing internal splint that allows mobilization, maintenance of alignment and extremity length until bridging callus forms. Mazda et al. treated 34 femoral shaft fractures in children with TENS. They observed the elastic properties of titanium provide a very good stability and its safe surgical treatment. ${ }^{14}$

Plate osteosynthesis in paediatric age group is associated with large exposure, relative longer duration of immobilization, risk of delayed union, infection and a second large dissection for plate removal. The external fixation provides good stability and early mobilization, but associated with pin tract infections and longer time for weight bearing. Interlocking nails have complications in children like avascular necrosis of femoral head and coxa valga. Ender nails and rush nails are the other alternative fixation for paediatric fracture shaft femur has poor rotational stability.

Buechsenschuetz et al. documented superiority of titanium nail and overall satisfaction compared to traction and casting. ${ }^{15}$ Ligier et al. treated 123 femoral shaft fractures in children with TENS with good result. ${ }^{16}$ Narayanan et al. found good outcome in 79 femoral fracture stabilized with TENS. 6 Heinrich et al. observed good results in 78 femoral fractures treated with Ender Nail. ${ }^{17}$

Fracture geometry and location is an important determinant for selection of surgical techniques. Transverse, short oblique and minimally comminuted fractures are suitable for TENS as stated by Flynn et al. ${ }^{2}$ Narayanan et al. stated that transverse, short oblique, short spiral fracture with minimum communication in the 5-12 years' age group were the best indication for TENS. ${ }^{6}$ Lacombes et al. states that TENS could be indicated in all femoral diaphyseal fracture of children above 6 years of age till epiphysis closed except severe type-III open fractures. 18

The most common complication of titanium elastic nail is entry irritation and pain. Other complications include limb length discrepancy, angulation of fractures, refracture and infection. Entry site irritations in our series were seen in 4 cases. We found that entry site irritation was significantly associated with long prominent nail end $(>2 \mathrm{~cm})$. All these findings were statistically significant.

\section{CONCLUSION}

The titanium elastic nail is an effective and viable treatment option in selected cases of femoral diaphyseal fracture in the 6-16 years' age group.

\section{REFERENCES}

1. Flynn JM, Hresko T, Reynolds RA, et al. Titanium elastic nails for pediatric femur fractures: a multicenter study of early results with analysis of complications. J Pediatr Orthop 2001;21(1):4-8.
2. Flynn JM, Skaggs DL, Sponseller PD, et al. The operative management of pediatric fracture of the lower extremity. J Bone jt Surg AM 2002;84(12):2288-300.

3. Buckley SL. Current trends in the treatment of femoral shaft fractures in children and adolescents. Clin Orthop Relat Res 1997;338:60-73.

4. Gwyn DT, Olney BW, Dart BR, et al. Rotational control of various pediatric femur fractures stabilized with titanium elastic nails. J Pediatr Orthop 2004;24(2):1727.

5. Flynn JM, Luedtke LM, Theodore J, et al. Comparison of titanium elastic nails with traction and spica cast to treat femoral fractures in children. J Bone Joint Surg Am 2004;86(4):770-7.

6. Narayanan UG, Hyman JE, Wainwright AM, et al. Complications of elastic stable intramedullary nail fixation of pediatric femoral fractures and how to avoid them. J Pediatr Orthop 2004;24(4):363-9.

7. Metaizeau JP. Stable elastic nailing for fractures of the femur in children. J Bone joint Surg Br 2004;86(7):9547.

8. Canale ST, Tolo VT. Fractures of the femur in children. J Bone joint Surg AM 1995;77:294-31.

9. Ward WT, Levy J, Kaye A. Compression plating for child and adolescent femur fractures. J Pediatr Orthop 1992;12:626-32.

10. Aronson J, Torsky EA. External fixation of femur fractures in children. J Pediatr Orthop 1992;12:157-63.

11. Bhaskar A. Treatment of long bone fractures in children by flexible titanium nails. Indian J Orthop 2005;39:1668.

12. Sanders JO, Browne RH, Mooney JF, et al. Treatment of femoral shaft by pediatric orthopedist: result of a 1998 survey. J Pediatr Orthop 2001;21:436-41.

13. Hunter JB. The principles of elastic stable intramedullary nailing in children. Injury 2005;36:A20-4.

14. Mazda K, Khairouni A, Pennecol GF, et al. Closed flexible intramedullary nailing of femoral shaft fractures in children. J Pediatr Orthop 1997;6(3):198-202.

15. Buechsenschuetz KE, Mehlman CT, Shaw KJ, et al. Femoral shaft fractures in children: traction and casting versus elastic stable intramedullary nailing. J Trauma 2002;53:914-21.

16. Ligier JN, Metaizeau JP, Prevot J, et al. Elastic stable intramedullary nailing of femoral shaft fractures in children. J Bone joint Surg Br 1988;70:74-7.

17. Heinrich SD, Drvaric DM, Darr K, et al. The operative stabilization of pediatric diaphyseal femur fractures with flexible intramedullary nails: a prospective analysis. J Pediatr Orthop 1994;14:501-7.

18. Lascombes P, Haumont T, Journeau P. Use and abuse of flexible intramedullary nailing in children and adolescents. J pediatr Orthop 2006;26:827-34. 